\title{
TRAJNOST ČELIČNIH KONSTRUKCIJA SA ASPEKTA KOROZIJE
}

\author{
Emir Maslak ${ }^{1}$ \\ Enis Sadović ${ }^{2}$
}

УДК: 620.193:624.014.2

DOI:10.14415/konferencijaGFS 2015.030

Rezime: U radu je analizirano štetno dejstvo korozije na konstrukcije. Priložen je prikaz korozionih modela koji se najčešće koriste kako bi se predvideo intenzitet ove degradacijske pojave kojoj su izložene sve čelične konstrukcije. Uzimajući u obzir brzinu napredovanja korozije, određene je vreme koje je neophodno da poprečni presek izgubi svoje efektivne površine kako bi jedan aksijalno pritisnuti element izbubio moć nošenja. U radu je korištena metoda modelovanja, odnosno štap je modeliran uz pomoć SHELL elemenata, i tražene veličine su sračunate metodom konačnih elemenata, uz pomoć savremenog softvera (ANSYS).

Ključne reči: korozija, trajnost, $M K E$

\section{UVOD}

Savremene građevinske konstrukcije najčešće se izvode od čelika, armiranog betona, drveta ili cigli (zidane konstrukcije). Koji materijal će biti korišćen za neku konstrukciju, zavisi od više parametara, a može biti određen i naklonošću projektanta. Čelik, kao građevinski materijal koji se intenzivno koristi u graditeljstvu, raspolaže izuzetnim karakteristikama koje su omogućile premošćavanje velikih raspona, projektovanja konstrukcija koje odgovaraju na kompleksne estetske zahteve, adaptilnost, funkcionalnost, itd.

Ono što predstavlja problem, kad su čelične konstrukcije u pitanju, je to što pri visokim temperaturama gube nosivost i što, kada su izloženi istovremenom dejstvu vode i vazduha, koroziraju. Korozija je negativna pojava iz prostog razloga što deo koji je zahvaćen korozivnim procesom umanjuje efektivni deo poprečnog preseka, što za posledicu ima smanjenje nosivosti jednog dela, ili cele konstrukcije.

Budući da je korozija jedan proces koji traje, cilj u ovom rada je da se odredi koliko će neki noseći elementi konstrukcije, koji su izloženi tom dejstvu, biti u stanju da nose opterećenje koje im pripada, a da stabilnost konstrukcije ne bude ugrožena.

\footnotetext{
${ }^{1}$ Emir Maslak, dipl.inž.građ., Državni Univerzitet u Novom Pazaru, Departman tehničkih nauka, Studijski program Građevinarstvo, Vuka Karadžića 66, Novi Pazar, Srbija, tel: 069 710117, e - mail: emaslak@np.ac.rs ${ }^{2}$ Enis Sadović, dipl.inž.građ. PhD student Univerziteta u Nišu, tel: 063494066, e-mail: enis_sadovic@yahoo.com
} 
International conference

Contemporary achievements in civil engineering 24. April 2015. Subotica, SERBIA

Ispitivani su aksijalno napregnut element rešetkastog nosača - centrično pritisnut. Rešetka koja je tretirana je glavni vezač krovne konstrukcije fiskulturne sale "Stana Bačanin" u Lešku.

Korišćena je metoda modelovanja, a za proračun iskorišćen je program ANSYS. Štap koji je predmet analize je tretiran uvažavajući i materijalnu i geometrijsku nelinearnost. Pritisnuti element je modeliran sa početnom imperfekcijom.

\section{KARAKTERISTIKE ČELIKA KAO GRAĐEVINSKOG MATERIJALA}

Čelik kao osnovni materijal za izradu nosećih konstrukcija u građevinarstvu ima specifična fizička, hemijska, mehanička i tehnološka svojstva. Fizička svojstva čelika su: boja, specifična težina, temperatura topljenja, elektroprovodljivost, magnetna svojstva, provodljivost toplote, specifična toplota i koeficijent toplotnog širenja.

Materijalni modeli, najčešće, se definišu na osnovu radnog dijagrama materijala (dobijenog eksperimentalnim putem) od kojih se konstrukcija izvodi. Kako bi ti modeli bili upotrebljivi u svakodnevnoj inžinjerskoj praksi, uvode se značajna pojednostavljenja, pa se materijal smatra:

- homogenim: materijal je istog sastava u svakom njegovom delu,

- izotropan: materijal ima iste mehaničke karakteristike u svim pravcima,

Čelik poseduje karakteristike koje su najpribližnije navedenim. Na slici 1 su dati radni dijagrami za dve vrste čelika koje su najviše u upotrebi.

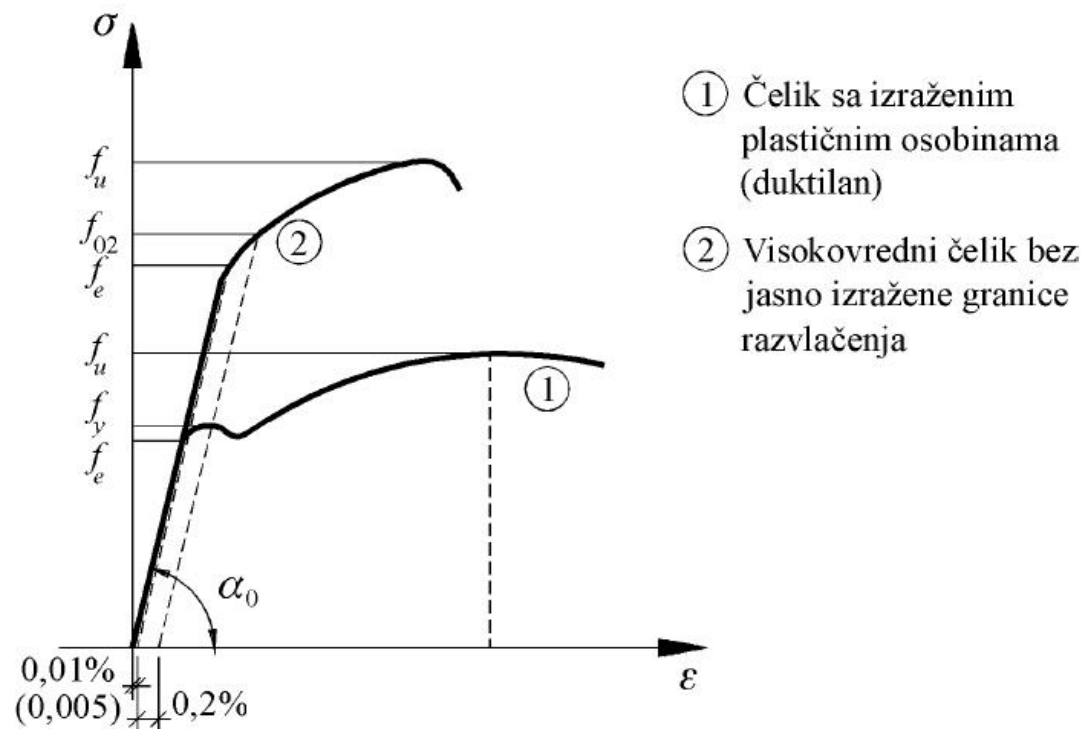

Slika 1. Radni dijagrami čelika 
Међународна конференција

Савремена достигнућа у грађевинарству 24. април 2015. Суботица, СРБИЈА

Drugi tip čelika je visokokvalitetni čelik. Odlikuje se velikom zateznom čvrstoćom, ali mu granica proporcionalnosti i granica tečenja nije jasno izražena. Lom nastupa relativno brzo, i zbog toga se ovi čelici nazivaju "krtim". Prvi tip čelika je obični čelik, kod koga je granica razvlačenja jasno izražena i, kao takav, ima mogućnost da istrpi velike deformacije u nelinearnom područiju. Zbog toga se ovaj tip čelika naziva i duktilan čelik i ima veoma široku primjenu u inžinjerskoj praksi.

\section{KOROZIJA}

Korozija čelika predstavlja elektrohemijski proces čiji je mehanizam u osnovi isti kao kod obične baterije kod koje dva metala, anoda i katoda, u provodljivoj sredini (elektrolitu) reaguju tako da se anoda razlaže i generiše se električna struja. Pri koroziji čelika jedan deo njegove površine ponaša se kao anoda, a drugi kao katoda. Delovi površine čelika koji su prekriveni česticama nečistoće ponašaju se kao anoda, dok se delovi koji su izloženiji kiseoniku (čistije površine) ponašaju kao katoda[1]. U hemijskoj reakciji na anodi dolazi do razlaganja gvožđa Fe na pozitivno naelektrisane jone gvožđa $\mathrm{Fe}^{++}$, pri čemu se oslobađaju elektroni. U hemijskoj reakciji na katodi dolazi do vezivanja kiseonika $\mathrm{O}_{2}$ i vode $\mathrm{H}_{2} \mathrm{O}$ sa oslobođenim elektronima, što prouzrokuje stvaranje negativno naelektrisanih jona hidroksida $(\mathrm{OH})^{-}$. Konačno, u kombinovanoj reakciji, spajanjem pozitivnih jona gvožđa $\mathrm{Fe}^{++}$i negativnih jona hidroksida $\left(\mathrm{OH}^{-}\right.$, dobija se hidroksid gvožđa $\mathrm{Fe}(\mathrm{OH})_{2}$, koji potom oksiduje u hidratisani oksid gvožđa $\left(\mathrm{Fe}_{2} \mathrm{O}_{3} \times \mathrm{H}_{2} \mathrm{O}\right)$, poznatiji kao rđa. Ovaj proces šematski je prikazan na slici 2.

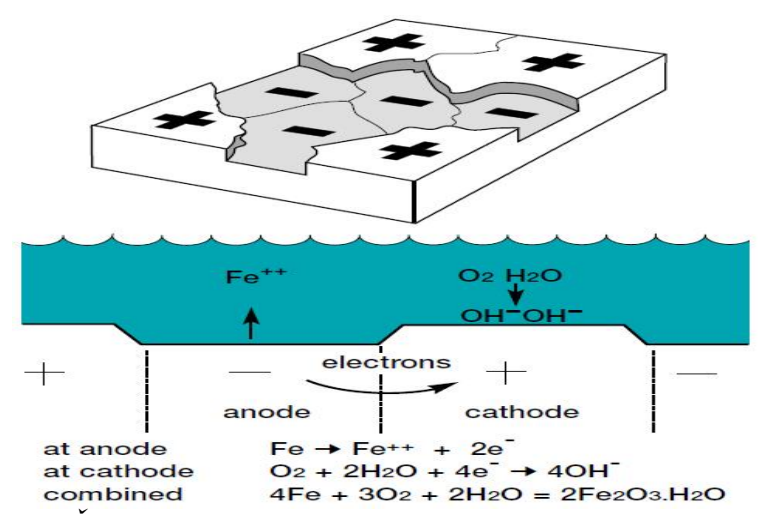

Slika 2. Šematski prikaz elektrohemijskog procesa korozije[2]

Korozija se manifestuje smanjenjem debljine čeličnog elementa, što posle dužeg perioda može da naruši nosivost i stabilnost čelične konstrukcije. Među najbitnijim faktorima koji utiču na razvoj korozije jeste okruženje u kojem se nalazi sama konstrukcija. Prema [3] objekti su klasifikovani u objekte u ruralnim okruženjima, objekte u urbanim okruženjima, objekte u industrijskim okruženjima, objekte u morskim okruženjima.

Problematika gubitka efektivnog poprečnog preseka usled korozije bila je predmet istaživanja u mnogim radovima. Jedna retrospektiva ovih modela data je u [4], na 
osnovu kojih se može videti da ti modeli mogu biti linearni, bilinearni, trilinearni i nelinearni. Jedan nelinearni model koji je tretiran sredstvima protiv-korozione zaštite je dat na slici 3 .

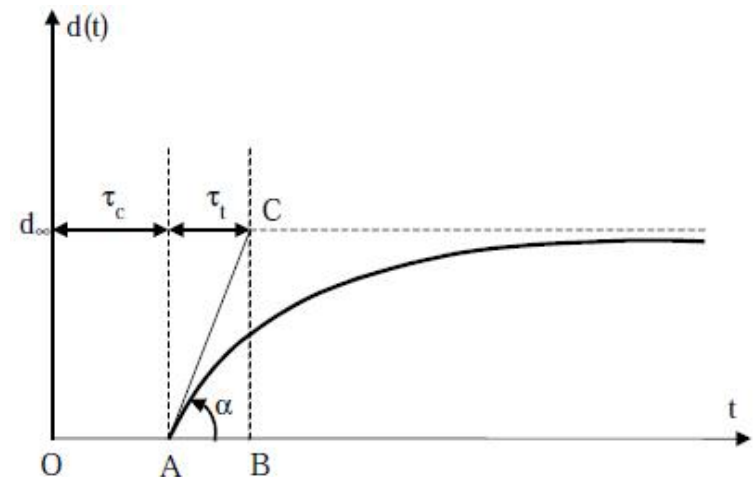

Slika 3. Smanjenje debljine elementa u funkciji vremena [4]

Kao što je već rečeno, najnepovoljnije dejstvo korozije na čeličnu konstrukciju ogleda se u gubitku debljine, a samim tim i površine poprečnog preseka koji učestvuje u procesu prenošenja opterećenja. Kada želimo u nekom modelu da pretstavimo ovaj gubitak preseka, to se, prema [5], najčešće radi na sledeće načine:

- korozija podjednako zahvatila sve delove poprečnog preseka (Uniformly Corroded),

- korozija, bilo po gornjoj bilo po donjoj površini elementa nasumično (randomly) raspoređenja,

- korozija oštećuje poprečni presek tako što se na elementu formiraju konusne jamice (cone type pitting corrosion).

U ovom radu je uzeto da je korozija podjednako zahvatila sve delovepoprečnog preseka sa brzinom napredovanja koja zavisi od sredini u kojoj se konstrukcija nalazi.

\section{NUMERIČKI PRIMER}

Konstrukcija koja je bila predmet analize u ovom radu je preikazana na Slici 4. U pitanju je krovni vezač industrujskog objekta izvedenog u obliku rešetke statičkog sistema proste grede. Raspon nosača je $24,84 \mathrm{~m}$ a visina u slemenu je $2.50 \mathrm{~m}$ (mereno osovinski). Nagib gornjeg pojasa mu je $3.90^{\circ}$.

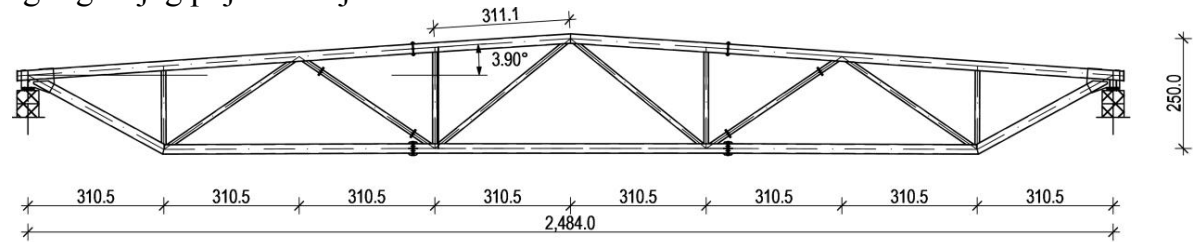

Slika 4. Izgled glavnog vezača

Svi štapovi rešetke su od cevastih profila (kružnog poprečnog preseka), i to pojasni štapovi i prva dijagonala su izvedeni od $\varnothing 219.10 \times 5.0 \mathrm{~mm}$, dok su štapovi ispune od 
Ø108.0x5.0mm profila. Za analizu dejstva korozije je izdvojen štap gorenjeg pojasa. Za početne parametre usvojen je intenzitet sile dobijen proračunom intenziteta $411.50 \mathrm{kN}$, što je približno $10 \%$ u odnosu na kritičnu sili pri kojoj nastupa izvijanje štapa. Model štapa, zajedno sa materijalnom modelom, je dat na slici 5.
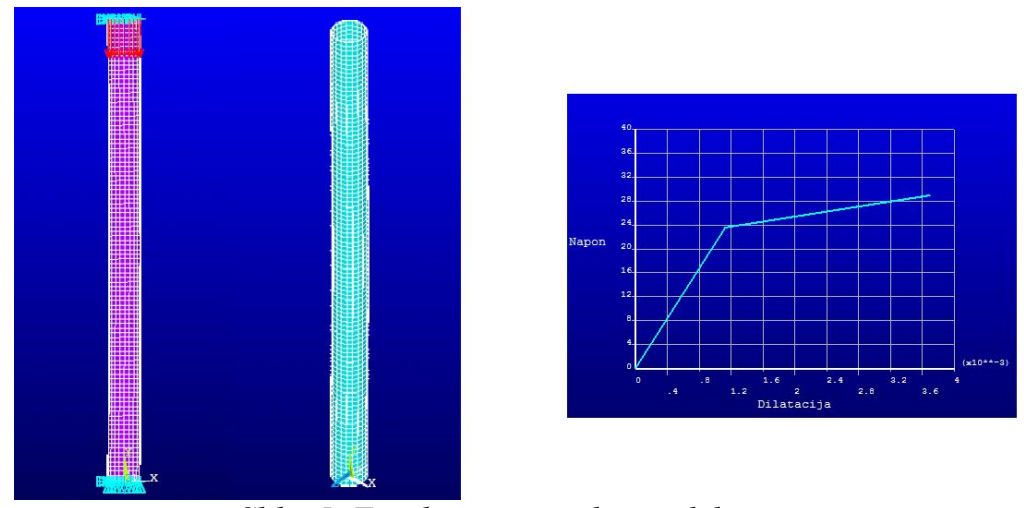

Slika 5. Fizički i materijalni model štapa

Materijalna nelinearnost je postignuta na taj način što je u materijalnom modelu radni dijagram pretpostavljen kao bilinearan, a geometrijska nelinearnost je postignuta modeliranjem štapa sa početnom geometrijskom imperfekcijom, koja, prema [6], iznosi l/500. Nosač je modeliran 2D SHELL elementom, i, u suštini, izgleda kao cilindrična ljuska.

\section{REZULTATI PRORAČUNA}

Proračun je sproveden na prikazanom modelu na taj način što mu je postepeno smanjivana debljina zida i na taj način pretstavljano gubljnje poprečnog preseka usled korozije. Debljina zida je smanjivana po celom poprečnom preseku, pa ovaj tip pretstavljanja korozije je prvi tip (Uniformly Corroded).

Pratila se promena veličine pomeranja sredine štapa. Svi ovi rezultati su sumirani tabelarno i aproksimativno su povezani za promenljivu - vreme. Rezultati dobijeni proračunom ovih podkoraka su dati u tabeli, dok je rezultat proračuna poslednjeg koraka prikazan na slici 6 .

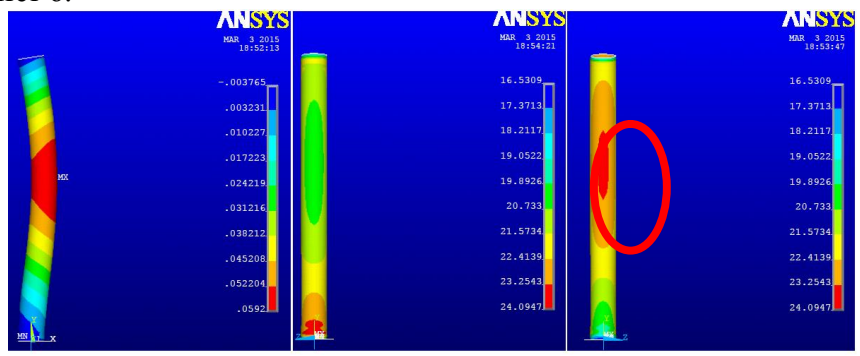

Slika 6 Rezultati proračuna za debljinu zida štapa od $2.75 \mathrm{~mm}$. 
International conference

Contemporary achievements in civil engineering 24. April 2015. Subotica, SERBIA

Na slici se može videti da su naponi na pojedinim mestima štapa prekoračili granicu razvlačenja, pa se može reći da je ovaj noseći element u ovom trenutku izgubio moć nošenja. Uzeto je da je napredovanje korozije u industrijskoj zoni $0.10 \mathrm{~mm} /$ godini, a u otvorenoj nezagađenoj sredini $0.05 \mathrm{~mm} /$ godini. Rezultati dobijeni proračunom su prikazani u formi tabele i dijagrama.

Tabela 1 Rezultati proračuna sa maksimalnim naponima i pomeranjima

\begin{tabular}{|l|c|c|c|c|c|c|c|c|c|}
\hline Debljina zida, $\boldsymbol{\delta}[\mathrm{cm}]$ & 0.500 & 0.450 & 0.425 & 0.400 & 0.375 & 0.350 & 0.325 & 0.300 & 0.275 \\
\hline Pomeranje, $\mathbf{X}[\mathrm{cm}]$ & 0.0299 & 0.0333 & 0.0353 & 0.0377 & 0.0403 & 0.0433 & 0.0469 & 0.0510 & 0.0592 \\
\hline Napon veći, $\boldsymbol{\sigma}_{\max }[\mathrm{kN} / \mathrm{cm} 2]$ & 13.002 & 14.443 & 15.290 & 16.243 & 17.323 & 18.557 & 19.981 & 21.534 & 24.095 \\
\hline Vreme, idustr. zona, $\mathbf{t}$ [god] & 0.0 & 5.0 & 7.25 & 10.0 & 12.50 & 15.0 & 17.50 & 20.0 & 22.50 \\
\hline Vreme, otvor. sred., $\mathbf{t}$ [god] & 0.0 & 10.0 & 14.50 & 20.0 & 25.0 & 30.0 & 35.0 & 40.0 & 45.0 \\
\hline
\end{tabular}

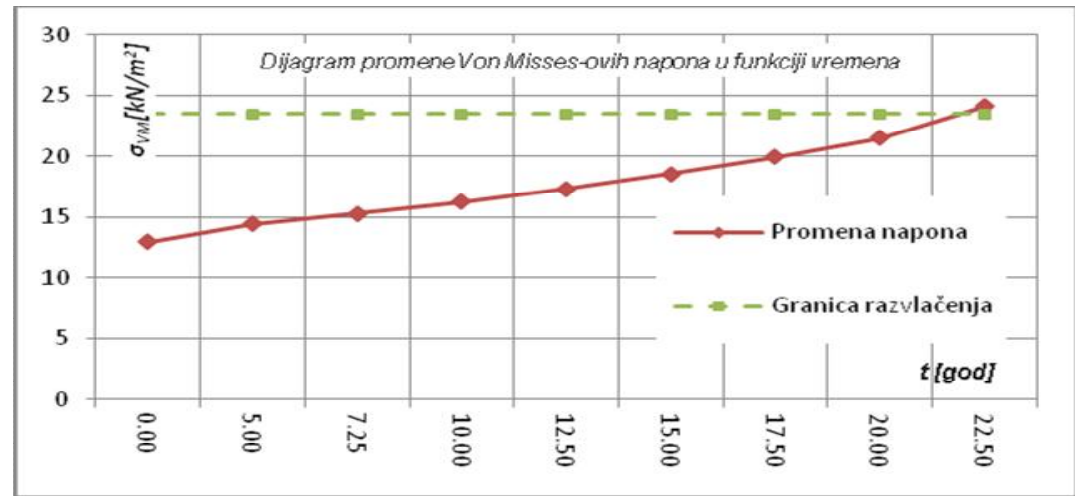

Dijagram 1. Promene Von Misses-ovih napona u funkciji vremena

\section{ZAKLJUČAK}

U [7] su dati osnovni zahtevi koji jedna konstrukcija u toku svog eksploatacionog veka mora da zadovolji, a odnose se na sigurnost (safety), uoptrebljivost (serviceability) i trajnost (durability).

Za svaku konstrukciju mora da bude računskim putem dokazano da su ova tri parametra zadovoljena, inače ta konstrukcija neće zadovoljiti parametar pouzdanosti (structural reliability). Predmet analize ovog rada je trajnost konstrukcije, i taj zahtev je, prema [11], definisan da konstrukcija mora da bude proračunata tako da njena degradacija (detorioration), posle isteka eksploatacionog veka ne utiče na smanjenje nivoa ponašanja konstrukcije ispod određene mere, imajući odgovarajući uvid u njenu sredinu i predviđeni nivo održavanja. U ovom radu je razmatran slučaj aksijalno pritisnutog štapa kružnog poprečnog preseka, sa zadatim mehaničkim i geometrijskim karakteristikama. Kao rezultat proračuna dobijeno je vreme koje će biti potrebno da nosač, usled gubitka poprečnog preseka, dovede u stanje kada više neće moći da izdrži opterećenje koje mu je namenjeno, zavisno od sredine (a samim tim i stepene agresivnosti) u kojoj se isti nalazi. $\mathrm{Na}$ osnovu svega izloženog vidi se da su ti uticaji, ukoliko se ne vodi računa o održavanju, izraženi. Ono šta bi mogao da bude naredni korak u istraživanju jeste da se 
Међународна конференција

Савремена достигнућа у грађевинарству 24. април 2015. Суботица, СРБИЈА

izvedu vremenske krive i za druge vrste naprezanja koja se najčešće javljaju u konstrukcijama. Moguće je i principima numerike izvesti i jednačine tih krivih linija kako bi u analitičkom obliku bilo moguće izvršiti predviđanje ponašanja cele konstrukcije ili jednog njenog dela kroz vreme, kada je u pitanju koroziono dejstvo.

\section{LITERATURA}

[1] Buđevac, D. et all: Metalne konstrukcije, Građevinska knjiga, Beograd, 2009

[2] Pringle, T.: Durability and exposed steel beams, Build, 2011.

[3] ISO 12944-2, Part 2: Classification of environments

[4] Qin, S., Cui, W.: Effect of corrosion models on the time-dependent reliabilityof steel plated elements, Marine Structures 16 (2003) 15-34, Elsavier.

[5] Mohammad R.K., et all: Strength of steel plates with both-sides randomly distributed with corrosion wastage under uniaxial compression, Thin-Walled Structures (2010), 325-342, Elsavier

[6] EN 1993-1-01 2005

[7] EN 1990: 2002, Evrokod 0

\section{DURABILITY OF STEEL STRUCTURES BY CORROSION ASPECT}

Summary: The paper analyzes the degradation effects of corrosion on structures. Corrosion models are presentated which are commonly used to predict the intensity of the degradation phenomena under which are exposed all steel structure. Taking into account the rate of progression of corrosion its been determined the time needed to cross-section loses its effective area so an axial pressed element lost its bearing capacity. Authors used the modeling method and element is modeled by SHELL elements, and the required results are calculated by finite element method, with the use of modern software (ANSYS).

Keywords: corrosion, durability, FEM 